\title{
\begin{tabular}{l|l} 
Mibraries & DSpace@MIT
\end{tabular}
}

\author{
MIT Open Access Articles
}

\section{Ultrahigh speed endoscopic swept source optical coherence tomography using a VCSEL light source and micromotor catheter}

The MIT Faculty has made this article openly available. Please share how this access benefits you. Your story matters.

Citation: Tsai, Tsung-Han, Osman O. Ahsen, Hsiang-Chieh Lee, Kaicheng Liang, Michael G. Giacomelli, Benjamin M. Potsaid, Yuankai K. Tao, et al. "Ultrahigh Speed Endoscopic Swept Source Optical Coherence Tomography Using a VCSEL Light Source and Micromotor Catheter." Edited by Melissa J. Suter, Stephen Lam, Matthew Brenner, Guillermo J. Tearney, and Thomas D. Wang. Endoscopic Microscopy IX; and Optical Techniques in Pulmonary Medicine (March 4, 2014). (C) 2014 Society of Photo-Optical Instrumentation Engineers (SPIE)

As Published: http://dx.doi.org/10.1117/12.2040417

Publisher: SPIE

Persistent URL: http://hdl.handle.net/1721.1/100219

Version: Final published version: final published article, as it appeared in a journal, conference proceedings, or other formally published context

Terms of Use: Article is made available in accordance with the publisher's policy and may be subject to US copyright law. Please refer to the publisher's site for terms of use. 


\title{
Ultrahigh Speed Endoscopic Swept Source Optical Coherence Tomography using a VCSEL Light Source and Micromotor Catheter
}

\author{
Tsung-Han Tsai ${ }^{1}$, Osman O. Ahsen ${ }^{1}$, Hsiang-Chieh Lee ${ }^{1}$, Kaicheng Liang ${ }^{1}$, Michael G. Giacomelli ${ }^{1}$, \\ Benjamin M. Potsaid ${ }^{1,2}$, Yuankai K. Tao ${ }^{1}$, Vijaysekhar Jayaraman ${ }^{3}$, Martin F. Kraus ${ }^{1,4}$, Joachim \\ Hornegger $^{4}$, Marisa Figueiredo ${ }^{5}$, Qin Huang ${ }^{5}$, Hiroshi Mashimo ${ }^{5}$, Alex E. Cable ${ }^{2}$, and James G. \\ Fujimoto $^{1}$ \\ ${ }^{1}$ Department of Electrical Engineering \& Computer Science and \\ Research Laboratory of Electronics, Massachusetts Institute of Technology, Cambridge, MA \\ ${ }^{2}$ Advanced Imaging Group, Thorlabs, Inc., Newton, NJ \\ ${ }^{3}$ Praevium Research, Inc., Santa Barbara, CA \\ ${ }^{4}$ Pattern Recognition Lab, University Erlangen-Nuremberg, Erlangen, Germany \\ ${ }^{5}$ Veterans Affairs Boston Healthcare System and Harvard Medical School, Boston, MA
}

\begin{abstract}
We developed an ultrahigh speed endoscopic swept source optical coherence tomography (OCT) system for clinical gastroenterology using a vertical-cavity surface-emitting laser (VCSEL) and micromotor based imaging catheter, which provided an imaging speed of $600 \mathrm{kHz}$ axial scan rate and $8 \mu \mathrm{m}$ axial resolution in tissue. The micromotor catheter was $3.2 \mathrm{~mm}$ in diameter and could be introduced through the $3.7 \mathrm{~mm}$ accessory port of an endoscope. Imaging was performed at 400 frames per second with an $8 \mu \mathrm{m}$ spot size using a pullback to generate volumetric data over $16 \mathrm{~mm}$ with a pixel spacing of $5 \mu \mathrm{m}$ in the longitudinal direction. Three-dimensional OCT (3D-OCT) imaging was performed in patients with a cross section of pathologies undergoing standard upper and lower endoscopy at the Veterans Affairs Boston Healthcare System (VABHS). Patients with Barrett's esophagus, dysplasia, and inflammatory bowel disease were imaged. The use of distally actuated imaging catheters allowed OCT imaging with more flexibility such as volumetric imaging in the terminal ileum and the assessment of the hiatal hernia using retroflex imaging. The high rotational stability of the micromotor enabled 3D volumetric imaging with micron scale volumetric accuracy for both en face and cross-sectional imaging. The ability to perform 3D OCT imaging in the GI tract with microscopic accuracy should enable a wide range of studies to investigate the ability of OCT to detect pathology as well as assess treatment response.
\end{abstract}

Keywords: Optical coherence tomography; Medical and biological imaging; Endoscopic imaging; Gastrointestinal; Three-dimensional imaging acquisition; Fiber optics imaging; Scanner; Medical optics instrument; angiography.

\section{INTRODUCTION}

Gastrointestinal (GI) cancer is one of the most common cancers in the United States and is highly lethal [1, 2]. By early detecting the pre-malignant lesion such as dysplasia in the GI tract, early treatment can be applied to achieve a high percentage of regression in patients with dysplasia [3], indicating the importance of early detection and treatment of dysplasia to prevent cancer progression in the GI tract. Several endoscopic imaging technologies have been developed to increase the yield of the endoscopy surveillance including narrow band imaging (NBI) [4, 5], chromoendoscopy (CE) [69], magnified endoscopy [10-12], confocal microendoscopy [13-18], and optical coherence tomography (OCT) [19-22]. OCT is a real-time optical imaging technique that is similar to ultrasonography in principle, but employs lasers instead of sound waves and allows depth-resolved images with near-microscopic resolution. Endoscopic OCT uniquely allows evaluation of broad and subsurface areas and can be used ancillary to standard endoscopy as an optical biopsy tool, but to date whether it can be used to identify dysplastic regions remains controversial [23, 24]. Current clinical endoscopic OCT systems are not able to provide good quality volumetric data sets due to the limitation of imaging speed and the scanning uniformity, so the true capability of OCT has not yet been fully realized in the endoscopic applications. In this study, we developed an ultrahigh speed endoscopic OCT imaging system for clinical gastroenterology using a high speed swept source and a micromotor based imaging catheter, and performed endoscopic OCT imaging in the human GI tract with a 10 folds higher imaging speed and dramatically improved scanning stability compared to commercially available

Endoscopic Microscopy IX; and Optical Techniques in Pulmonary Medicine, edited by Guillermo J. Tearney,

Thomas D. Wang, Melissa J. Suter, Stephen Lam, Matthew Brenner, Proc. of SPIE Vol. 8927, 89270T

(C) 2014 SPIE · CCC code: $1605-7422 / 14 / \$ 18 \cdot$ doi: $10.1117 / 12.2040417$

Proc. of SPIE Vol. $892789270 T-1$ 
endoscopic OCT systems. High quality volumetric data sets covering large areas in the GI tract not only allow visualization of the tissue structure in any orientation, but also provide more structural information including angiograms at microscopic resolution that helps accurately detect dysplastic lesion.

\section{METHOD}

The ultrahigh speed endoscopic OCT system used in this study, as shown in Figure 1, illuminated tissue using a $1.3 \mu \mathrm{m}$ VCSEL light source with a sweep rate of $600 \mathrm{kHz}$ and tuning range of $120 \mathrm{~nm}$. Circumferential, cross-sectional images at 400 frames per second using a total of 1,500 axial scans per image were acquired. The total image acquisition time was 8 seconds for each volumetric data set. The axial resolution was $8 \mu \mathrm{m}$ in tissue, given the estimated refractive index of tissue is 1.38, and the sensitivity was $\sim 101 \mathrm{~dB}$. Each image frame was flattened according to the sheath surface of the imaging catheter before three-dimensional volume rendering, which allows better en face visualization. All crosssectional and en face images shown below are formed by averaging the volumetric data over $20 \mu \mathrm{m}$ thick section to reduce speckle noise.

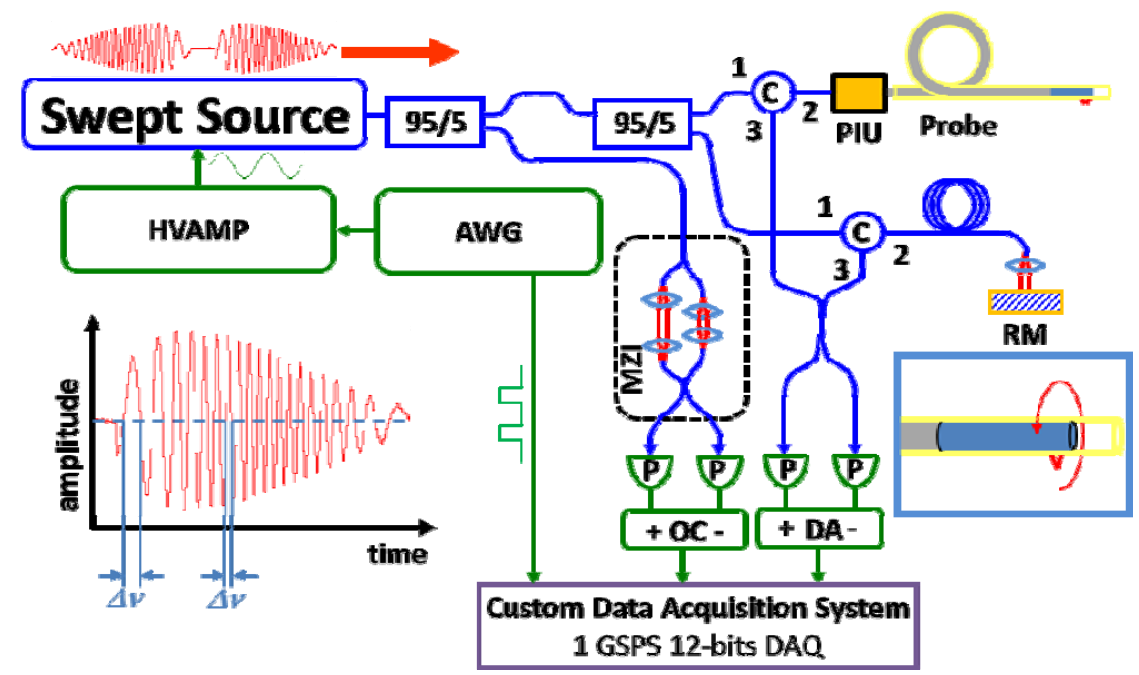

Figure 1. Schematic of swept source OCT system (optics: blue; electronics: green). Right inset showing the catheter indicates the rotary scanning direction of the focused spot. Left inset shows the principle of optical frequency clock (OFC) generation using the MZI output. Zero crossings are unevenly spaced in time, but evenly spaced in optical frequency v. C: circulator; MZI: Mach-Zehnder interferometer; RM: reference mirror; DA: differential amplifier; P: photodetector; PIU: patient interface unit; AWG: arbitrary waveform generator; HVAMP: high voltage amplifier.

Figure 2 shows the schematic of the imaging catheter used in the study, which is the same imaging catheter design published in [25]. The spot size was $15 \mu \mathrm{m}$ (FWHM) in tissue. By pulling the optical and motor assembly from the proximal end of the torque coil during the rotary image acquisition, a spiral scanning pattern could be performed. The catheter had a $3.2 \mathrm{~mm}$ outer diameter and $18.2 \mathrm{~mm}$ rigid length and could pass through a $3.7 \mathrm{~mm}$ endoscope working channel. The micromotor could rotate uniformly with an imaging frame rate from 20 fps to $1,200 \mathrm{fps}$. In this study, a frame rate of 24,000 rpm ( $400 \mathrm{fps}$ ) and a pullback speed of $2 \mathrm{~mm} / \mathrm{s}$ were used to acquire the 3D-OCT data sets. The total length of the torque coil and sheath for the prototype catheter was 2 meters.

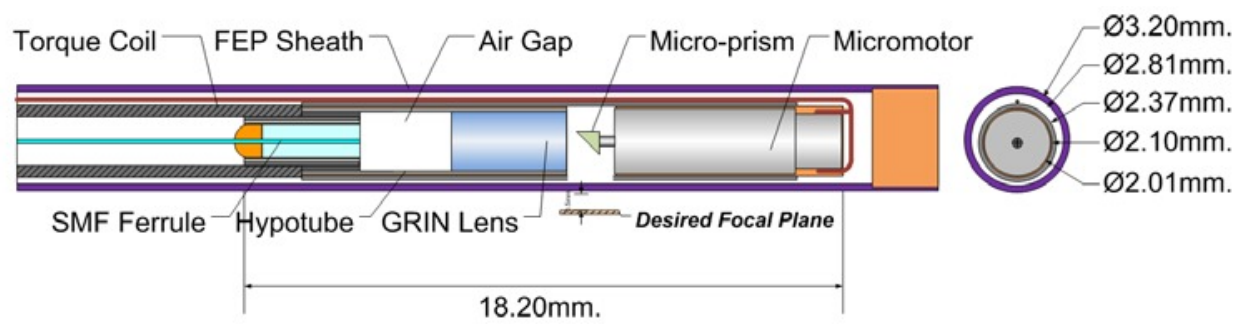

Figure 2. Schematic diagrams of the micromotor-based imaging catheter using the dual sheaths design. 


\section{RESULTS}

Figure 3 shows volumetric OCT acquired in a patient with dysplasia. The en face view (Fig. 3a) shows the branching and elongated pit pattern of HGD without applying any exogenous contrast agent, which was confirmed by histology shown in Fig. 3d.

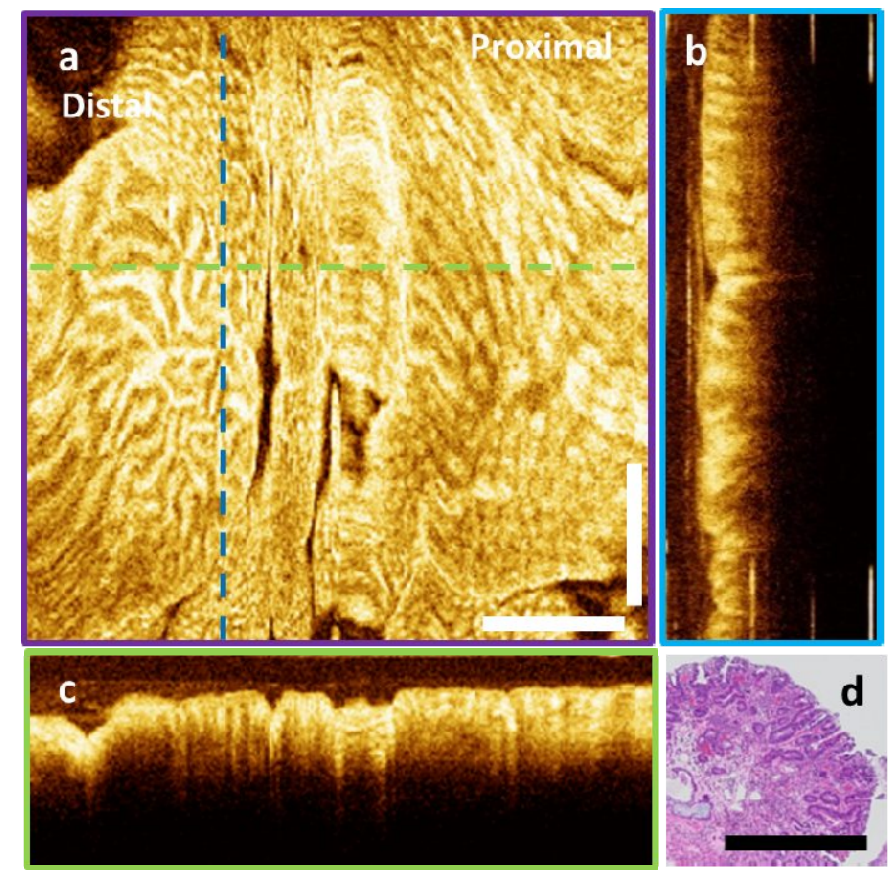

Figure 3. Volumetric OCT data set of Barrett's esophagus with high grade dysplasia acquired using the ultrahigh speed endoscopic OCT system. (a) En face view at the imaging depth of $200 \mu \mathrm{m}$ shows branching characteristics of the dysplastic $\mathrm{BE}$ structure. (b) Cross-sectional image along the pullback direction shows the glandular structure of BE which lost the organized layered structure as normal esophagus. (c) Cross-sectional image along the rotary (fast scan) direction shows the glandular structure of BE with high grade dysplasia. (d) Corresponding histology taken at the imaged location confirmed focal high grade dysplasia. Scale bar: $1 \mathrm{~mm}$.

Figure 4 shows the volumetric OCT imaging with the catheter placed on top of the normal terminal ileum (TI). Fig. 4a shows an en face OCT image centered at a tissue depth of $50 \mu \mathrm{m}$, corresponding to the top surface of the villi structure. The en face image on the terminal ileum surface shows similar structure observed in the endoscopic view but with high magnification, allowing better evaluation of the morphology of the duodenum. Fig. $\mathbf{4 b}$ shows another en face OCT image centered at a tissue depth of $300 \mu \mathrm{m}$, corresponding to the base of the ileum villi. The round, crypt-like structure can be distinguished in the en face image at the depth, showing the transverse cross-section of the villi. Fig. 4c and Fig. 4d show cross-sectional images along the pullback and rotary direction. The Preyer's patches can be observed in Fig 4c as the thick, hyposcattering layer between the hyperscattering lamina propria and submucosa layers. The imaged terminal ileum area was biopsied immediately after the OCT imaging for histology comparison. Fig. 4e shows the corresponding histology and it was diagnosed as a normal terminal ileum, consistent with the observation of the OCT images. The depth of the standard biopsy barely reaches the muscularis mucosa, while OCT images consistently show as deep as the submucosa layers with much larger coverage, suggesting endoscopic OCT can be used as an imaging-guided biopsy tool to minimize the sampling error of random biopsy, which is the current gold standard of diagnosis.

Figure 5 shows a preliminary volumetric OCT data acquired in a patient with normal esophagus using the imaging system. Fig. 5b shows the world's first endoscopic OCT angiography of the vascular structure in the lamina propria of the esophagus. OCT angiography detects blood flow by rapidly rescanning overlapping image planes and measuring decorrelation generated by motion [26-33]. OCT angiography generates 3D images of subsurface vasculature without requiring exogenous contrast. These results demonstrated high speed and high resolution imaging of architectural morphology and vascular structure. 

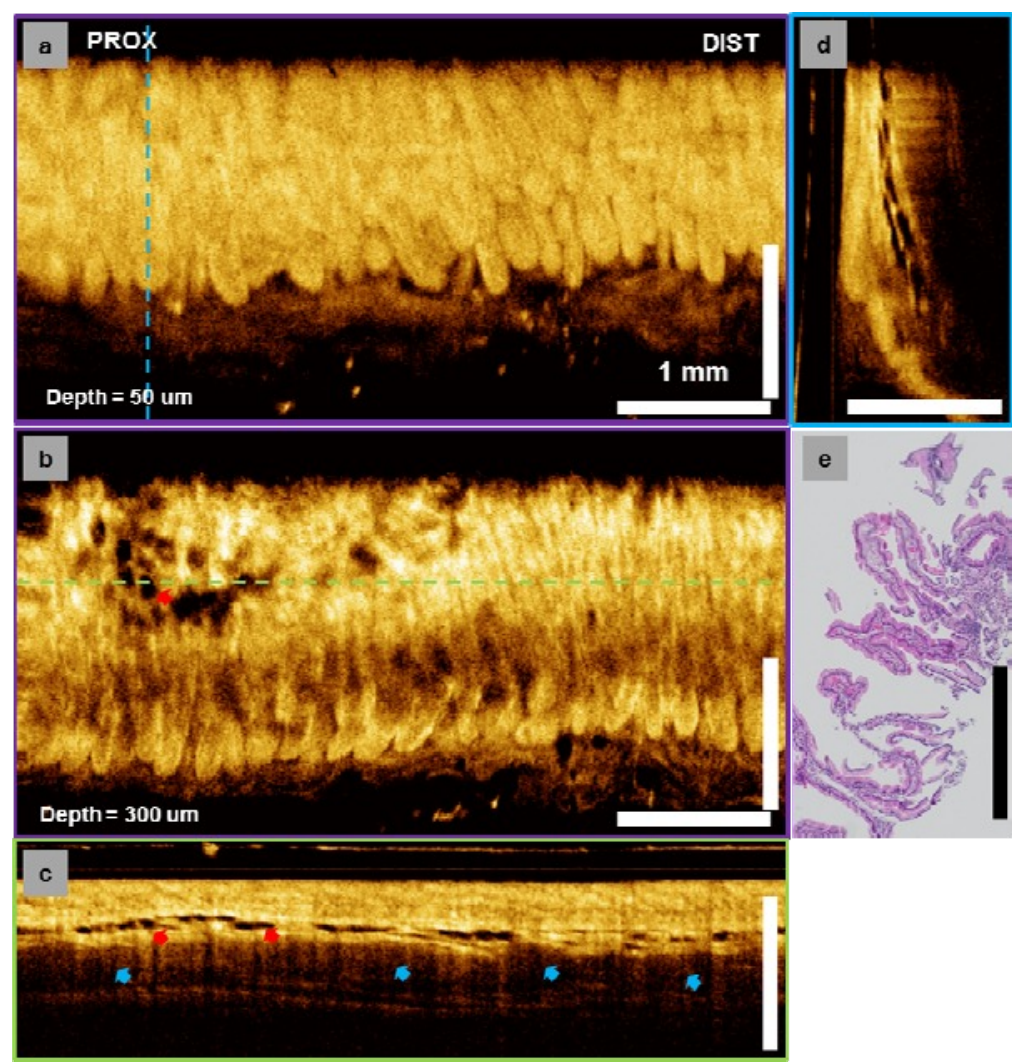

Figure 4. In vivo imaging of the terminal ileum. (a) En face image at the imaging depth of 50 um shows typical villi structure. (b) En face image at the imaging depth of 300 um shows a numerous of glandular structure underneath the tissue surface. (c) Cross-sectional image along the pullback direction. (d) Cross-sectional image along the rotary direction. (e) Corresponding histology of the terminal ileum, which is diagnosed as a normal ileum. Red arrow: ileum glands. Blue arrows: Preyer's patches.
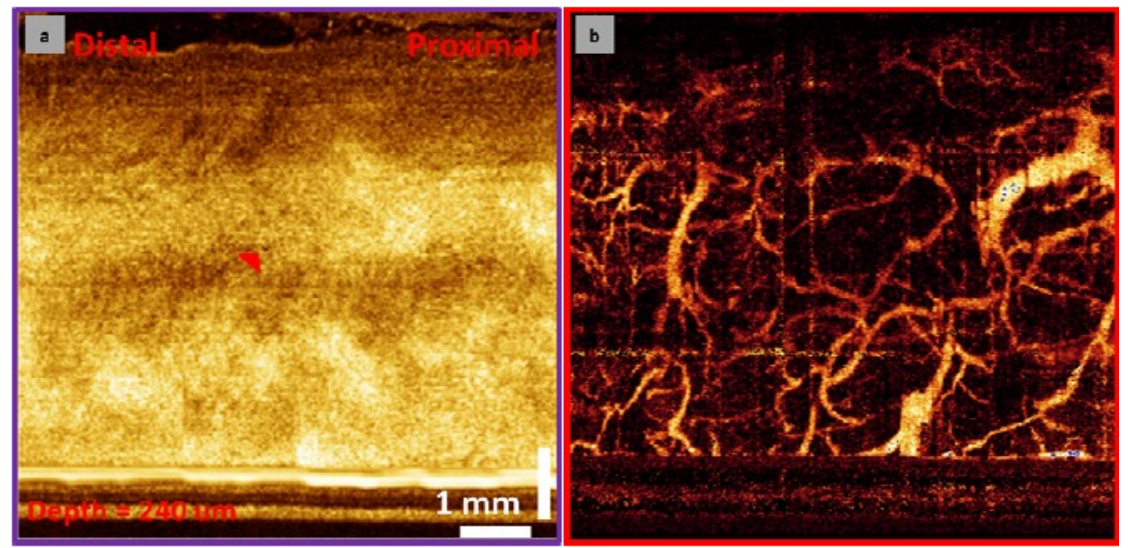

Figure 5. Volumetric OCT of normal human esophagus with a micromotor imaging catheter. (a) En face image at a depth of $240 \mu \mathrm{m}$ shows buried glands indicated by red arrows. (b) OCT angiography shows vasculature at same imaging depth.

In conclusion, this clinical pilot study demonstrated the in vivo detection of dysplastic lesions in the GI tract using ultrahigh speed endoscopic OCT imaging based on both en face pit pattern and cross-sectional surface maturation with near-microscopic resolution. With the high scanning stability and high imaging speed, endoscopic OCT angiography was also performed in the human GI tract, showing the capability of differentiating the 3D microvasculature between normal and diseased tissues without the need of exogenous contrast agents. The ability to visualize both 3D morphologic 
structure and vasculature in the GI tract not only enables comprehensive diagnosis of GI diseases but also opens a whole new window of investigating tumor-associated neovascularization and the research of vessel-related diseases.

\section{ACKNOWLEDGEMENT}

The research was sponsored in part by the National Institute of Health R01-CA75289-17, R44-CA101067-06, R44EY022864-01, R01-EY011289-27, R01-HL095717-04 and R01-NS057476-05; the Air Force Office of Scientific Research FA9550-10-1-0063 and Medical Free Electron Laser Program FA9550-10-1-0551, and German Research Foundation DFG-GSC80-SAOT and DFG-HO-1791/11-1. THT acknowledges support from the Center for Integration of Medicine and Innovation Technology.

\section{REFERENCE}

[1] "Cancer Facts and Figures," American Cancer Society2013.

[2] A. Jemal, R. Siegel, E. Ward, T. Murray, J. Q. Xu, and M. J. Thun, "Cancer statistics, 2007," Ca-a Cancer Journal for Clinicians, vol. 57, pp. 43-66, Jan-Feb 2007.

[3] B. F. Overholt, M. Panjehpour, and J. M. Haydek, "Photodynamic therapy for Barrett's esophagus: follow-up in 100 patients," Gastrointestinal Endoscopy, vol. 49, pp. 1-7, Jan 1999.

[4] P. Sharma, A. Bansal, S. Mathur, S. Wani, R. Cherian, D. McGregor, A. Higbee, S. Hall, and A. Weston, "The utility of a novel narrow band imaging endoscopy system in patients with Barrett's esophagus," Gastrointestinal Endoscopy, vol. 64, pp. 167-175, 2006.

[5] R. Singh, G. K. Anagnostopoulos, K. Yao, H. Karageorgiou, P. J. Fortun, A. Shonde, K. Garsed, P. V. Kaye, C. J. Hawkey, and K. Ragunath, "Narrow-band imaging with magnification in Barrett's esophagus: validation of a simplified grading system of mucosal morphology patterns against histology," Endoscopy, vol. 40, pp. 457,463, 09.06.2008 2008.

[6] M. I. F. Canto, S. Setrakian, J. E. Willis, A. Chak, R. E. Petras, and M. V. Sivak, "Methylene blue staining of dysplastic and nondysplastic Barrett's esophagus: An in vivo and ex vivo study," Endoscopy, vol. 33, pp. 391-400, May 2001.

[7] P. Sharma, M. Topalovski, M. S. Mayo, and A. P. Weston, "Methylene blue chromoendoscopy for detection of short-segment Barrett's esophagus," Gastrointestinal Endoscopy, vol. 54, pp. 289-293, Sep 2001.

[8] T. Endo, T. Awakawa, H. Takahashi, Y. Arimura, F. Itoh, K. Yamashita, S. Sasaki, H. Yamamoto, X. F. Tang, and K. Imai, "Classification of Barrett's epithelium by magnifying endoscopy," Gastrointestinal Endoscopy, vol. 55, pp. 641-647, May 2002.

[9] J. Pohl, A. May, T. Robenstein, O. Pech, M. Nguyen-Tat, A. Fissler-Eckhoff, and C. Ell, "Comparison of computed virtual chromoendoscopy and conventional chromoendoscopy with acetic acid for detection of neoplasia in Barrett's esophagus," Endoscopy, vol. 39, pp. 594-598, Jul 2007.

[10] S. E. Kudo, S. Tamura, T. Nakajima, H. O. Yamano, H. Kusaka, and H. Watanabe, "Diagnosis of colorectal tumorous lesions by magnifying endoscopy," Gastrointestinal Endoscopy, vol. 44, pp. 8-14, Jul 1996.

[11] "The Paris endoscopic classification of superficial neoplastic lesions: esophagus, stomach, and colon - November 30 to December 1, 2002," Gastrointestinal Endoscopy, vol. 58, pp. S3-S43, Dec 2003.

[12] A. Axon, M. D. Diebold, M. Fujino, R. Fujita, R. M. Genta, J. J. Gonvers, M. Guelrud, H. Inoue, M. Jung, H. Kashida, S. Kudo, R. Lambert, C. Lightdale, T. Nakamura, H. Neuhaus, H. Niwa, K. Ogoshi, J. F. Rey, R. Riddell, M. Sasako, T. Shimoda, H. Suzuki, G. N. J. Tytgat, K. Wang, H. Watanabe, T. Yamakawa, and S. Yoshida, "Update on the Paris classification of superficial neoplastic lesions in the digestive tract," Endoscopy, vol. 37, pp. 570-578, Jun 2005.

[13] T. Wilson, "Confocal microscopy," Academic Press: London, etc, vol. 426, pp. 1-64, 1990.

[14]D. R. Sandison and W. W. Webb, "Background rejection and signal-to-noise optimization in confocal and alternative fluorescence microscopes," Applied Optics, vol. 33, pp. 603-615, 1994.

[15] G. S. Kino and T. R. Corle, Confocal scanning optical microscopy and related imaging systems: Academic Press, 1996.

[16] J. Pawley, Handbook of biological confocal microscopy: Springer, 2006.

[17] A. L. Polglase, W. J. McLaren, and P. M. Delaney, "Pentax confocal endomicroscope: a novel imaging device for in vivo histology of the upper and lower gastrointestinal tract," Expert Rev Med Devices, vol. 3, pp. 549-56, Sep 2006.

[18] K. B. Dunbar and M. I. Canto, "Confocal endomicroscopy," Techniques in Gastrointestinal Endoscopy, vol. 12, pp. 90-99, 2010. 
[19] D. Huang, E. A. Swanson, C. P. Lin, J. S. Schuman, W. G. Stinson, W. Chang, M. R. Hee, T. Flotte, K. Gregory, C. A. Puliafito, and J. G. Fujimoto, "Optical Coherence Tomography," Science, vol. 254, pp. 1178-1181, Nov 221991.

[20] S. H. Yun, G. J. Tearney, B. J. Vakoc, M. Shishkov, W. Y. Oh, A. E. Desjardins, M. J. Suter, R. C. Chan, J. A. Evans, I. K. Jang, N. S. Nishioka, J. F. de Boer, and B. E. Bouma, "Comprehensive volumetric optical microscopy in vivo," Nature Medicine, vol. 12, pp. 1429-1433, Dec 2006.

[21] D. C. Adler, Y. Chen, R. Huber, J. Schmitt, J. Connolly, and J. G. Fujimoto, "Three-dimensional endomicroscopy using optical coherence tomography," Nature Photonics, vol. 1, pp. 709-716, Dec 2007.

[22] M. J. Suter, B. J. Vakoc, P. S. Yachimski, M. Shishkov, G. Y. Lauwers, M. Mino-Kenudson, B. E. Bouma, N. S. Nishioka, and G. J. Tearney, "Comprehensive microscopy of the esophagus in human patients with optical frequency domain imaging," Gastrointestinal Endoscopy, vol. 68, pp. 745-753, 2008.

[23] J. A. Evans, J. M. Poneros, B. E. Bouma, J. Bressner, E. F. Halpern, M. Shishkov, G. Y. Lauwers, M. MinoKenudson, N. S. Nishioka, and G. J. Tearney, "Optical Coherence Tomography to Identify Intramucosal Carcinoma and High-Grade Dysplasia in Barrett’s Esophagus," Clinical Gastroenterology and Hepatology, vol. 4, pp. 38-43, 2006.

[24] A. D. Aguirre, Y. Chen, B. Bryan, H. Mashimo, Q. Huang, J. L. Connolly, and J. G. Fujimoto, "Cellular resolution ex vivo imaging of gastrointestinal tissues with optical coherence microscopy," Journal of Biomedical Optics, vol. 15, Jan-Feb 2010.

[25] T.-H. Tsai, B. Potsaid, Y. K. Tao, V. Jayaraman, J. Jiang, P. J. S. Heim, M. F. Kraus, C. Zhou, J. Hornegger, H. Mashimo, A. E. Cable, and J. G. Fujimoto, "Ultrahigh speed endoscopic optical coherence tomography using micromotor imaging catheter and VCSEL technology," Biomed. Opt. Express, vol. 4, pp. 1119-1132, 2013.

[26] S. Makita, Y. Hong, M. Yamanari, T. Yatagai, and Y. Yasuno, "Optical coherence angiography," Optics Express, vol. 14, pp. 7821-7840, Aug 2006.

[27] J. Fingler, D. Schwartz, C. H. Yang, and S. E. Fraser, "Mobility and transverse flow visualization using phase variance contrast with spectral domain optical coherence tomography," Optics Express, vol. 15, pp. 12636-12653, Oct 12007.

[28] Y. K. Tao, A. M. Davis, and J. A. Izatt, "Single-pass volumetric bidirectional blood flow imaging spectral domain optical coherence tomography using a modified Hilbert transform," Optics Express, vol. 16, pp. 12350-12361, 2008.

[29] A. Mariampillai, B. A. Standish, E. H. Moriyama, M. Khurana, N. R. Munce, M. K. K. Leung, J. Jiang, A. Cable, B. C. Wilson, I. A. Vitkin, and V. X. D. Yang, "Speckle variance detection of microvasculature using swept-source optical coherence tomography," Optics Letters, vol. 33, pp. 1530-1532, 2008.

[30] L. An and R. K. K. Wang, "In vivo volumetric imaging of vascular perfusion within human retina and choroids with optical micro-angiography," Optics Express, vol. 16, pp. 11438-11452, 2008.

[31] B. J. Vakoc, R. M. Lanning, J. A. Tyrrell, T. P. Padera, L. A. Bartlett, T. Stylianopoulos, L. L. Munn, G. J. Tearney, D. Fukumura, R. K. Jain, and B. E. Bouma, "Three-dimensional microscopy of the tumor microenvironment in vivo using optical frequency domain imaging," Nature Medicine, vol. 15, pp. 1219-U151, Oct 2009.

[32] L. F. Yu and Z. P. Chen, "Doppler variance imaging for three-dimensional retina and choroid angiography," Journal of Biomedical Optics, vol. 15, Jan-Feb 2010.

[33] Y. Jia, J. C. Morrison, J. Tokayer, O. Tan, L. Lombardi, B. Baumann, C. D. Lu, W. Choi, J. G. Fujimoto, and D. Huang, "Quantitative OCT angiography of optic nerve head blood flow," Biomedical Optics Express, vol. 3, Dec 1 2012. 